\title{
Towards a sustainable quality of university research: knowledge sharing
}

\author{
Nor Ashmiza Mahamed \\ Ismail ${ }^{1}$, Christine Welch ${ }^{1}$ and \\ Mark Xu' \\ ${ }^{1}$ Portsmouth Business School, University of
Portsmouth, U.K.
}

Correspondence: Nor Ashmiza Mahamed Ismail, Portsmouth Business School, University of Portsmouth, Richmond Building, Portland Street, Portsmouth PO1 3DE, U.K. Tel: +44 0239284 8484;

E-mail: ash.mahamed@port.ac.uk

\begin{abstract}
It is claimed that by providing a sustainable environment, a university's research profile can be enhanced. Questions then arise about how universities define sustainability, what criteria are used to judge sustainable quality in research, and how a university can maintain sustainable research quality? This paper places emphasis on sustainable quality of research from the perspective of knowledge sharing. It is argued that effective sharing of knowledge among academics could lead to improved university research performance. It is most important that universities establish credible leadership influences on knowledge sharing. We apply Beer's Viable System Model to identify those domains of research leadership and knowledge sharing that are necessary for an institution to maintain sustainable quality in research. This paper considers examples of research-knowledge sharing in U.K. research communities, and explores a positive relationship between research leadership and research-knowledge sharing.

Knowledge Management Research \& Practice advance online publication, 12 August 20 I3; doi: $10.1057 / \mathrm{kmrp} .2013 .39$
\end{abstract}

Keywords: sustainability; knowledge sharing; research leadership

\section{Introduction}

The term 'sustainability' in relation to research suggests the ability to maintain a certain rate or level of activity within higher education institutions (HEIs) (Oxford Dictionaries, 2013). Use of this term in the discourse of higher education (HE) policy suggests the perception of threats to continued research activity from the current political and social environment. Certainly, it can be seen in Western countries, such as the U.K., U.S.A., and Australia, that the political and economic climate is not conducive to generous funding for research. A survey in the United States revealed that $40 \%$ of respondents saw a decline in federal funding as the most important trend affecting the overall research environment (Welker \& Cox, 2006). In the U.K., research activity is sometimes seen by the public as a distraction from the real business of teaching, and of dubious value at a time when University tuition fees have increased substantially. Governments may embrace the rhetoric of economic development through research and innovation, but the pot of money available to support it is limited by competition with other demands on the public purse. In this climate, competition for available funding is increasing and even in the traditional centres of 'excellence' in the old universities resources are limited. At the same time, those institutions deemed to be 'research informed' rather than 'research led' have difficult choices to make. While teaching is the primary source of income, it is not sufficient to secure future prosperity. Not only does research output generate direct income for HEIs through the Research Councils, it also enables income generating activity through knowledge transfer to industry and commerce. Research outputs form the basis of
Received: 7 May 2013

Revised: 17 June 2013

Accepted: 18 June 2013 
worldwide university rankings, which in turn influence the ability of an institution to market its services and attract international students. Sustainable research is thus vital to on-going financial stability.

Formal acknowledgement of the need to consider sustainability can be found in policy statements relating to HE. The Australian Government, for instance, began a Sustainable Research Excellence initiative in 2009-10:

(The initiative) recognises that achieving research excellence on a sustainable basis is dependent on universities' capacity to strategically manage their resources to meet costs associated with research activities. It also recognises a need for mechanisms and incentives to support universities to stretch their research performance over time. (Australian Government, 2009, n.p.)

Examples can be found in individual university initiatives, for example. in the U.K., Bournemouth University's Institute for Media \& Communication Research publishes a policy for 'Building a Sustainable Research Environment' by, inter alia, establishing international networks, mentoring schemes for new researchers, and encouraging collaboration at all levels of research (Bournemouth University, 2012, n.p.).

The issue has also been taken up by the research councils, for example the ESRC invites applications for funding for Capacity Building Clusters, saying that:

It is vital that the UK maintains a strong supply of skilled people to enable the research base, in collaboration with business and civil society sector organisations, to ... respond to unforeseen challenges; identify future opportunities; increase the international competitiveness of UK businesses and organisations. (ESRC, 2012)

With sustainability in mind, attention within HEIs turns towards capacity building in research. Clearly every institution will approach this task from a unique policy perspective depending upon its particular mission and mix of activities. However, there are some common themes that may be identified. The UKCDS, a collaboration of 14 U.K. funders and stakeholders with an interest in international development research, suggests that capacity building should be seen as an iterative and flexible process' and not a one-off task (DFID, 2010). It goes on to suggest:

Effective $C B$ is the result of the interplay between individual, organisational, network and institutional factors. It is difficult to plan in advance which steps will need to be taken or which dynamics will evolve, but planning is nevertheless essential to develop a shared vision and strategy. Its development can be pursued and facilitated by a process of action learning and continuous adaptation of interventions in the light of experience.

Clearly, this suggests there is no quick fix that can be adopted by HEIs. However, a number of factors are highlighted for attention. These include building upon existing strengths; support for leaders and change agents from within the system to be developed; consideration of wider organisational development needs; regular assessment of skills and resource needs, including the IT infrastructure; and consideration of group dynamics. Furthermore, the Department for International Development issues guidance on communication of research (DFID, 2005), which points out that, It is also important to ensure representation and involvement in decision making of stakeholders at different levels, including those whose voice is not usually heard.

Hazelkorn (2004) points out that the market for HE is now global and that research is a core element of its mission. A focus for many institutional research strategies is therefore to Sustain academic and professional reputation in the knowledge-based economy. Among the key challenges of research capacity building are, in her view, poor infrastructure, lack of a critical mass of researchers, staff without the necessary skills or resources, academic workload tensions and lack of research tradition. Attempts to identify 'best practice' have identified, inter alia, a need to build a 'culture of scholarship'.

\section{Research culture}

Stehlik (2005) reflects that there is no widespread agreement as to the nature of a research culture, and it is likely that this varies between disciplines. McRoy et al (2011), writing in the context of social work, outline specific leadership strategies senior managers can adopt to promote access to research funding; encourage interdisciplinary research; enhance mentorship relationships between senior and junior researchers; and recruit new staff strategically. Care is needed when generalising across disciplines in this respect, since scholars from different backgrounds embrace differing methods and epistemologies, which in turn affect the culture of research. With this caveat, it is possible to examine some views on the importance of research culture.

Pete Downes, Principal and Vice Chancellor at the University of Dundee, describes its (successful) research culture as comprising the following elements: selective recruitment to bring in high calibre researchers; collaboration to become competitive; respect and value for the contributions of all staff, including support staff; and celebration of one another's success (Downes, 2011). He goes on to highlight the role of universities in innovation, suggesting that this role needs to be a more active one in the future, ensuring not only that research findings are disseminated but that they are exploited through knowledge transfer partnerships. He suggests that a successful research culture continues to promote 'curiosity-driven research' but that it needs to abandon the passivity of traditional knowledge dissemination and seek instead to capture the economic impact of investment.

Knowledge sharing appears to be a key part of a strong research culture, whether this is collaboration in interdisciplinary research, sharing ideas with a mentor or partner, or through a knowledge transfer exercise in which ideas can be shared and exploited for gain. Taking on board the views of Downes about the need for active research cultures in 21st century HEIs, the crucial role of knowledge 
sharing is encapsulated in the following statement by Senge (1998):

\begin{abstract}
Sharing knowledge is not about giving people something, or getting something from them. That is only valid for information sharing. Sharing knowledge occurs when people are genuinely interested in helping one another develop new capacities for action; it is about creating learning processes. (Senge, 1998, p 11)
\end{abstract}

\section{Knowledge sharing in research culture}

Why would academics choose to share or not share their research knowledge? Of course, dissemination of results is a normal outcome of the research process. However, knowledge sharing behaviour at earlier stages in that process may be more problematic. Many have discussed the influence of extrinsic and intrinsic motivation in knowledge sharing. A quantitative study by Hung et al (2011) in a university in Taiwan found that intrinsic reward (i.e. reputation feedback) has the strongest significant effect to support research knowledge sharing (RKS) as compared to extrinsic rewards. Motivation comes from factors such as developing a body of knowledge, contributing to the university, enhancing research performance, enhancing teaching quality, looking for co-authorship, and performing well in research assessment exercises, career development, and networking. Of course, extrinsic rewards also play a role in motivating academics to share research knowledge (Bandyopadhyay \& Pathak, 2007). Thus, an extrinsically motivated research-academic may engage in RKS because s/he wants to enhance the university's research performance but also add value to his/her own research profile, potentially enhancing her/his value in the global market for research-academics.

Research-academics sometimes fear losing power and competitive value if they share their research knowledge, particularly at early stages in a project. Hence, they tend to hoard their research-knowledge (Mahamed Ismail et al, 2013). This is particularly true of early career researchers who may be lacking in confidence or savoir-faire in research matters. RKS is most likely to occur when there is trust among colleagues or with research-leaders, and conversely least likely when there is fear that colleagues may steal ideas before they become developed and intellectual property is protected. The tendency increases with the amount of time academics have invested in carrying out tasks related to a project.

Wang \& Noe (2010) conclude that organisational culture is one of the key determinants of knowledge sharing. In HEIs settings, research culture is critical for RKS. Importantly, there appears to be a distinction between pre-1992 and post-1992 universities in the U.K. concerning this issue. A study by Mahamed Ismail (2012) involved semi-structured interviews with both academics and research-leaders in eight U.K. university business schools across the binary divide. She finds that there is a clear dichotomy between research leadership in pre-1992 and post-1992 universities. Research culture in pre-1992 universities is more established. They have strong explicit cultures, which are successful in developing, implementing, and maintaining effective research policies, and strong implicit cultures around research (Mahamed Ismail et al, 2013).

The elements that differentiate the implicit culture in pre- and post-1992 universities can be summarised into four different aspects, the first of which is research capability. Due to the nature of the so-called 'researchintensive' universities, new academics are automatically exposed to knowledge sharing behaviour. They are aware at all career stages of the need to be involved in RKS, where the ultimate aim is to achieve higher ranked publications. RKS engagement is embedded in research-academics' beliefs and norms. In turn, this engagement is seen to enhance their research savoir-faire and confidence to engage in RKS. In contrast, academics in post-1992 universities are disadvantaged. Since the nature of these universities is more 'teaching-intensive', research-active academics have had less exposure to RKS. In consequence, the numbers of research-academics who are active in RKS are relatively small, and research savoir-faire and confidence among research colleagues may be lacking.

The second element is research-academics' behaviour. Those in pre-1992 institutions appear more self-motivated. Their engagement in RKS is not driven or compelled by the university research policies. In these 'research-intensive' universities, every academic is aware of the need to engage in RKS and aim for more research output. This is their raison d'être. Conversely, in post-1992 universities, the involvement of academics in RKS is found to be primarily extrinsically driven. Although they are aware of the importance of engagement with RKS for their career prospects, smaller numbers are naturally motivated to engage in RKS without being driven or controlled by other factors. Due to the more 'teaching-intensive' nature of post-1992 universities, a majority of academics are not intrinsically driven to engage in RKS but require encouragement from university research policies.

Third, RKS engagement styles differ. In pre-1992 universities, academics appear more independent. As a result, their RKS engagement is more scattered, so that researchacademics tend to work in isolated groups, leading to an atmosphere of individualism within the university. In post-1992 universities, however, where academics appear to be less independent, RKS involvement is more clustered. Academics are more likely to work in groups. Research centres play important roles here, often as the primary source of funding or expertise. This creates the atmosphere of collectivism characterising post-1992 universities.

The fourth, and perhaps most important, element is research leadership. It has been noted that research-leaders in pre-1992 universities, particularly professors, use an interactive approach to support RKS among academics. The interactive approach includes giving advice, guidance, and assistance in terms of good practice of RKS. Through this approach, academics will have opportunities to seek knowledge in terms of research ideas, designs, or methodologies; create links based on professors' networks 
for RKS purposes; and develop research ideas that can enhance RKS engagement and enrich research output. In contrast, research-leaders in post-1992 universities, particularly professors, are less likely to provide interactive leadership with their junior colleagues. Despite the greater degree of collectivism, RKS support is more 'top-down', with an emphasis on developing and implementing research policies rather than building up close relationships among research-academics. They tend to support RKS by focusing on the 'what' factors - what is to be done and what is expected of academics - giving less emphasis to 'how' factors, such as engagement with knowledge sharing and networking. Whitmore (1992) suggests that concentration on these 'what' factors can actually inhibit achievement of 'how' factors by academics, with a consequent detrimental effect on university research performance. In order to promote sustainability, it may be critical for the post-1992 universities to improve their implicit research culture, in order to improve the commitment and motivation of academics for RKS.

\section{Research leadership}

One empirical study of knowledge management (Chawla \& Joshi, 2010) shows how leadership plays an essential role in creating, developing, and managing organisational capabilities, by creating effective teams; building and integrating culture; promoting use of IT and other supportive infrastructures; and development of rewards and recognition systems. Islam et al (2011) in their empirical work have confirmed that leaders who take positive initiatives in ensuring that necessary support and organisational structures are in place are able to facilitate knowledge sharing among different functional groups. This suggests that, in an HE context, research-leaders could have a significant influence on RKS engagement among research-academics.

Pre-1992 research-leaders are not only supportive of RKS through the development and implementation of research strategy, but also through daily interactions with other academics, formal or informal. Mahamed Ismail shows that research-leaders across all levels in pre-1992 universities take positive steps to provide an encouraging atmosphere, in order to facilitate RKS among academics. Most importantly, professors in pre-1992 universities are found to use an interactive approach to promote and motivate research-academics towards RKS engagement. The interactive relationships between professors and researchacademics show no particular boundaries. Overall, the influences of research-leaders in pre-1992 universities give academics more exposure to RKS, leading to greater confidence to become engaged themselves, and thus develop research savoir-faire. This study confirms that the support given by research-leaders is significantly related to RKS engagement among academics, and to the quality of research performance.

In contrast, Mahamed Ismail's study shows that research-leaders in post-1992 universities are successful in setting up, developing, and implementing systematic research policies to enhance research performance. The best have had some measure of success in recent years in closing the performance gap with the so-called 'researchintensive' universities. On the other hand, they have overlooked the need for more specific encouragement and guidance for junior academics. Researchers need leaders not only to communicate with them about policy, and tell them what they are expected to produce, but to facilitate their learning process concerning RKS. This vital role, traditionally performed by professors in the pre-1992 sector, appears not to be addressed in the 'research-informed' sector.

This view is supported by work carried out by Fliaster (2004) and Chatzoglou \& Vraimaki (2010), outside of the HE context. They showed that by breaking down the hierarchies, organisations can create openness in communication, which allows people to contribute to practices and share knowledge in the workplace. The roles of professors are probably crucial to effective knowledge sharing in academia, as they are the closest to the researchacademics within departments, subject groups, teams, or even at the individual level, and can demonstrate successful research within the same or similar disciplines. Bandura (1997) suggests that leading by example exhibits a leader's commitment to his/her work and offers guidance to subordinates on how to attain effective performance, enhancing subordinates' efficacy through observational learning.

Professors should act as 'knowledge builders', who create opportunities and processes that stimulate RKS among academics. They should become the research 'trendsetters' for the school, department, or subject group, who take the lead in research, not only by providing targets or a vision, but also a positive influence on the informal research culture. Professors are the 'sounding board' for researchacademics, whose suggestions, advice, and reactions provide inspiration to engage in RKS. Their roles are not only to inspire, but, importantly, to re-motivate researchacademics when inevitable rejections and setbacks occur. They have a role in congratulating successful researchers and promoting a celebration of research achievements, helping to consolidate a positive research culture.

Mahamed Ismail's study has suggested three key enablers of knowledge sharing - people, organisation, and IT. A model of context-specific RKS was developed (see Figure 1), integrating the three enablers together. People highlights the key roles of research-leaders in supporting and promoting RKS; organisation indicates the establishment of both explicit and implicit cultures; and IT signifies the development of technological infrastructures that support knowledge sharing. The model also incorporates the sequential process of RKS, from knowledge hoarding to knowledge seeking, and knowledge sharing. These three enablers need to be in balance to bring about sustainable university research performance.

\section{The university as a system}

A university can be conceived as one particular type of organisation, that is a complex, purposive social system 


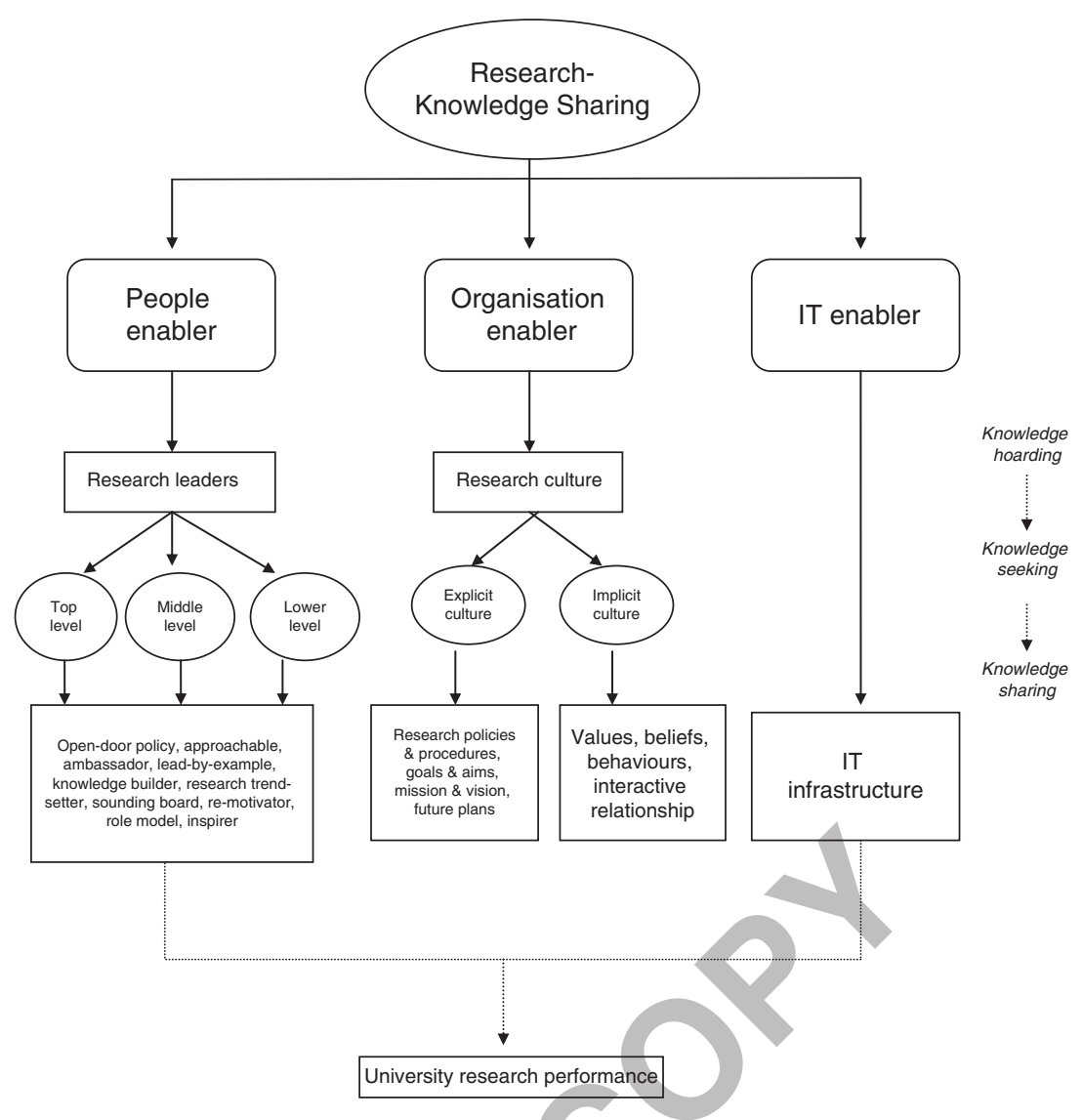

Figure 1 The impact of knowledge sharing on research performance (Mahamed Ismail et al, 2013).

created in order to bring about and maintain some desired transformation in its environment (Argyris \& Schön, 1978). In the case of universities, multiple purposes are contemplated, reflecting multiple 'environments' and transformations: students to graduates through education; what is unknown into 'knowledge' through research; uninformed to informed clientele through knowledge transfer. Organisational systems are comprised of individual members who are themselves purposeful, intentionally and collectively formulating objectives (Ackoff \& Emery, 1972). However, an organisation is more than just a collective. It is the interactions among members in their multiple, contextually dependent roles, which generates those perceived emergent properties that characterise a particular organisation as a purposeful system (Bednar, 2007). If any part of a system changes or leaves, the effect is reflected in a change to the state of the system as a whole (Ackoff \& Emery, 1972). Thus, in a university context, individual academics will each have their own worldviews from which their individual aspirations are constructed. They will formulate their own projects/objectives for research outcomes upon which to build careers, interacting with one another both within and beyond their home university, both to collaborate and to compete in the scholarly communities of academic disciplines. Their individual objectives may or may not be congruent from time to time with the aims and purposes of the wider university system, whose environment includes influences from business, from government and from society generally. Thus, universities have a problem in that they resource the academic systems from which new knowledge is generated, and depend upon the collective reputation of the faculty for on-going prosperity, but they never truly own either the means of production of knowledge, nor the fruits of academic labour. How may this problem be addressed in order to create sustainable university systems?

In the remainder of this paper, we examine the ideas of sustainability in research, and management of academic communities. It will be suggested that a command-andcontrol perspective on management may threaten such sustainability and that management focusing on facilitation, and especially leadership, will be more successful. The Viable Systems Model (VSM) (Beer, 1985) is used to illustrate the importance of supportive organisational design, and reflections on a study by Mahamed Ismail et al (2013) are used illustrate the crucial role of research leadership in promoting sustainability.

\section{Requisite variety, stability, and sustainability}

A viable system is one that can maintain a stable relationship with its environment, and hence sustain its performance, through appropriate feedback. A viable system 


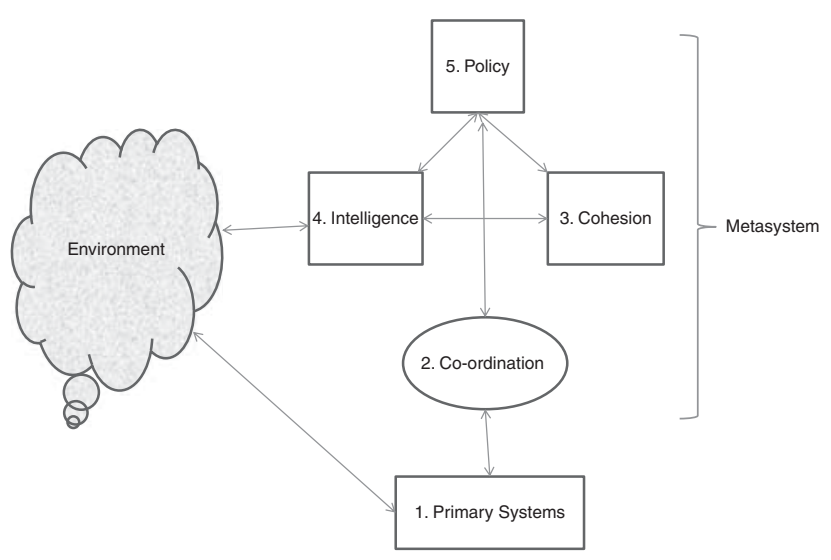

Figure 2 Elements of the VSM.

balances the demands of its environment by acting effectively as a coherent whole. Beer (1985) derived his concept of 'viability' of systems through reflections upon Ashby's (1956) Law of Requisite Variety. This 'law' states that only variety can absorb variety (variety being the number of discernibly different states that a dynamic system can occupy). Variety in the system as a whole must match the variety of its interactions with its environment in order for stability to be maintained over time. Clearly, for a very complex system (such as a university) it is not possible to enumerate all of the possible states it can occupy. It follows that a system to control such an organisation must have the flexibility to match or exceed the variety of its operational units (those that are responsible for delivery of its primary outputs), or seek to reduce their variety.

\section{The VSM}

Beer considered the requirements for viability in systems by reflecting upon the ways in which balance is achieved in the human body, through three interacting parts. First, Operations - in the context of the body this is the organs and the muscles, which carry out all its primary functions. Second, the coordinating Metasystem that ensures all the various operational units work together in an integrated and harmonious way - achieving internal balance. The third part is the Environment - those parts of the outside world, which are directly relevant to the system in focus. Operational units must maintain balance with the Environment if the system is to remain viable. Many examples exist of practical application of the VSM to real-world organisations (examples can be found, for instance, in Espejo \& Reyes, 2011) Figure 2.

VSM helps us to consider a system in terms of the necessary elements that can enable it to form an integrated whole capable of the sustained pursuit of purposeful activity. Thus, we begin by asking what operational activities the system in focus needs to perform (System 1) and what needs to be managed in order to facilitate this (the coordinating Metasystem). Within this Metasystem, four systems interact. System 2 is concerned with communication and coordination, maintaining the stability of the whole by smoothing out conflicts that arise. In any set of coordinated activities with an overall common aim, there are likely to be conflicts of interest and differences of opinion. Once stability has been achieved, the job of System 3 must be addressed: how to optimise interactions in order to achieve the aims of the whole. System 3 must be designed to address synergy within the whole by taking a continuous overview of the complexities of the system. This aspect of the Metasystem is dependent upon effective feedback from operational units and its essential task is to regulate System 1. Aspects of System 3 must therefore be designed to ensure that resources are available to each of the operational units, sufficient to their individual needs but managed in order to gain maximum utility overall. There is an interaction (feedback loop) between Systems 3 and 2 , since it will be necessary to deliberate on the optimal use of scarce resources and resolve any ensuing conflicts. There is also an interaction with System 4 here (see below) since the Metasystem will need to consider provision for future stability and/or growth. Forward planning, based on interpretations of feedback from System 3, and from intelligence gathered from the Environment, is the business of System 4 . This aspect of the coordinating Metasystem monitors the whole, in conjunction with Systems 2 and 3, and considers adaptations that are necessary to future stability and achievement of common aims. System 4 is also responsible for reputational issues, representing the whole as a viable system to the outside world. System 5 addresses the shared identity of the whole. It pulls the system towards achievement of its overall purpose, providing ground rules for all activities of participating units, together with means for enforcing them. This is what we often refer to as policymaking and it is closely related to governance. System 5 depends upon communication from all the other aspects of the Metasystem in order to fulfil its role effectively.

Where VSM forms the basis for organisational design, an important principle emerges. At every level, each subsystem must itself fulfil the criteria for viability, including all the elements of the model. If the organisation fails to match environmental complexity it will inevitably fail. This may be because its performance falls short of customer expectations, government regulation, availability of resources, or any of a plethora of reasons since environmental complexity has no inherent limit. Balance can only be achieved by reducing complexity or by matching it. Thus, every sub-system in a viable system must itself be viable according to the model, that is. viable systems are recursive. Since tacit knowledge is the key to management of variety at operational level, internal autonomy must balance. Imbalance in organisational complexity, for instance through arbitrary approaches to management, can lead to the loss of effective control. A balance may be achieved only by amplifying management variety and attenuating organisational variety; and by amplifying the organisational response and (where possible) attenuating environmental variety. As Hoverstadt (2008) points out, 
attempts to centralise control in a complex system are doomed to failure since no individual or oligarchy can hope to match its inherent variety.

\section{Designing viable systems}

Hoverstadt (2008) suggests that there are a number of potential drivers of complexity, depending upon the primary task(s) addressed by the organisation. These include technology (what operational units must do); geography (the location of the service delivery); customers (who they are and their characteristics); time (when and at what intervals service delivery is required). Unfolding of structure in a viable system needs to follow the natural flow of work. Primary activities may be made up of other primary activities, for which customers are internal. Care is needed when redesigning organisational structure so that balance is maintained and there is no unintentional decoupling between support activities and the primary activities they are intended to serve. Autonomy in one primary activity system may impinge on and disrupt another and coordination is needed to prevent or control such disturbances. The need for System 2 intervention increases with the number of activities, degree of interdependence between them, and degree of co-incidence in their potential impact on the environment. Interdependence may be external or internal: one primary activity may be the customer of another. Coordination is needed at each level of recursion and poor design of System 2 could be detected through performance measurement, incidence of chaotic activity, problems that recur or conflict between operational teams. Shared 'language' and organisation culture are important System 2 features (Hoverstadt, 2008, p. 107). Coordination challenges reflect the tension between the autonomy of operational units and a need for synergy across the system as a whole. Identifying and removing unnecessary complexity (e.g. by streamlining processes) is clearly beneficial in this respect.

The next aspect of the Metasystem (System 3) addresses 'getting things done'. This will involve a bargaining process between management and constituent sub-systems within a viable system, exchanging resources for performance. Care is needed here since rigid budgetary controls can cause dysfunction, as primary units may engage in practices designed to increase autonomy and flexibility. Within VSM, autonomy within agreed limits is indicated so that there can be a flexible response to deployment by those with the required tacit knowledge. Performance measurement is crucial here and needs to be designed so as to be both adequate and appropriate at every level of recursion in organisational structures. Hoverstadt (2008), interpreting Beer's model, suggests that monitoring is needed in these circumstances, that is. opportunities to explore actual practice within the operational unit(s) concerned, rather than gathering of statistical measures.

'Future' management is the focus of System 4 within the Metasystem. Development is needed to ensure a good fit is maintained between an organisation and the environment within which it operates. Change is endemic in any environment and a viable system must be prepared to cope with on-going change. Thus, a part of the activity in System 4 will be external communication and intelligence gathering. Intelligence looks for strategic gaps and opportunities to close them - this drives evolution and therefore maintenance of viability. Building capacity for knowledge creation and exploitation through innovation is a key role of System 4 (development). Its job is to build organisational flexibility and capability, holding the whole together over time. It has often been observed that an undue emphasis on efficiency can undermine System 4 activities through 'short termism'. This is characterised by constant 'fire fighting' activities by management. Careful design of System 4 is therefore crucial in building a sustainable system. Misguided command-and-control management approaches often treat all operational units as if they are alike, imposing change from above. However, since they are not alike in their primary activities, differences in the rate of adaptation are inevitable. Collaboration between Systems 2 and 4 is therefore critical to cohesion of the system as a whole. This is needed to address the resource and coordination issues involved in balancing internal and external complexities through modelling of current and future desired states of the system.

Managers often seek to identify 'best practice' as a guide to the future. However, what is perceived to be 'best' reflects only a snapshot of the balance between operational and environmental complexities at a given moment in time, in a particular organisational system. Disturbances in the environment require a flexible response and therefore any identified practice may not remain 'best' beyond the short term, as these disturbances impact upon the system. The intelligence gathering role of System 4 must be designed to cope with this potential paradox. Perceiving environmental disturbances, making explicit strategic gaps that are identified, and opening up those gaps, are tasks belonging to System 4, but closing those gaps is the province of Systems 5 and 3. There will always be a need to maintain balance between the different aspects of the Metasystem.

The roles performed by a well-designed System 5 relate to organisational identity. This is manifest in activities we tend to group under the headings of policy and governance. Clearly, a system that loses its integration and shared views of identity ceases to be viable, since the tensions between management and operations and between operations and environment are likely to become overwhelming. System 5 is concerned with balancing variety among all of these elements that would threaten synergy. A commandand-control approach often distorts and misrepresents the roles of System 5, leading to sub-optimisation and consequent fragmentation.

\section{VSM in the design of HE systems}

The VSM can be useful in designing systems for sustainability. Figure 3 shows how organisational systems often 


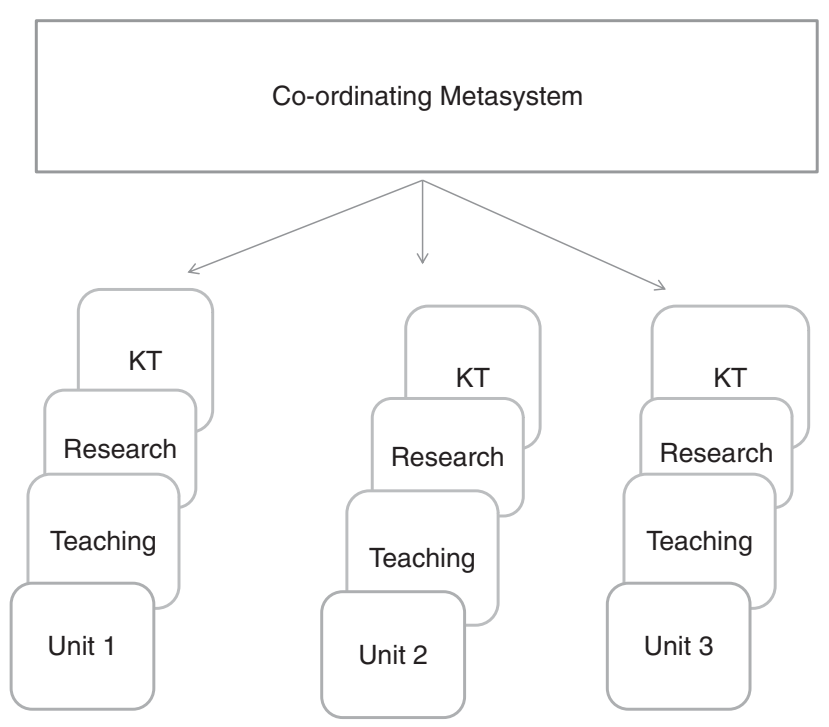

Figure 3 System 1 fragmentation in HEls.

appear in HEIs, with fragmentation of System 1 activities within separate, discipline-related silos. Each of these silos is likely to be involved in several aspects of the HEI mission, possibly teaching, research and knowledge transfer. These may be competing for the same scarce resources. As we have seen (above) staff in post-1992 institutions have expressed a view that they are prevented from engagement with research and knowledge sharing due to pressure of the teaching load. The coordinating system often takes the form of a physically and hierarchically remote management structure, which tends to exacerbate rather than tackling this fragmentation. This fragmentation will inevitably lead to sub-optimality in the system as a whole as each unit seeks to pursue its own objectives and to optimise its performance at the expense of the whole. One major challenge for proponents of sustainable research will be to overcome this sub-optimality, either through restructuring or appropriate interventions from Systems 2 and 3.

HEIs need to consider the activities and structures appropriate to System 2. Espejo \& Reyes (2011, p. 29) discuss perspectives on the nature of communication. They point out that many people espouse a paradigm of message transmission, believing that information can be transferred over channels from one person to another. Such a view limits the responsibility of the 'sender' to ensuring that the message (e.g. a policy statement) has been received safely - an essentially one-way process. However, this interpretation is problematic when considering System 2 within VSM. Here, communication goes much further to embrace coordination of actions. The responsibility of the communicator here is to engage in a circular process of negotiation: sender-receiver-sender, and to do this simultaneously to embrace the activities of all System 1 units, coordinating their actions and smoothing out conflicts. The context of U.K. HE makes this a daunting task. Fragmentation of activities is likely to mean that

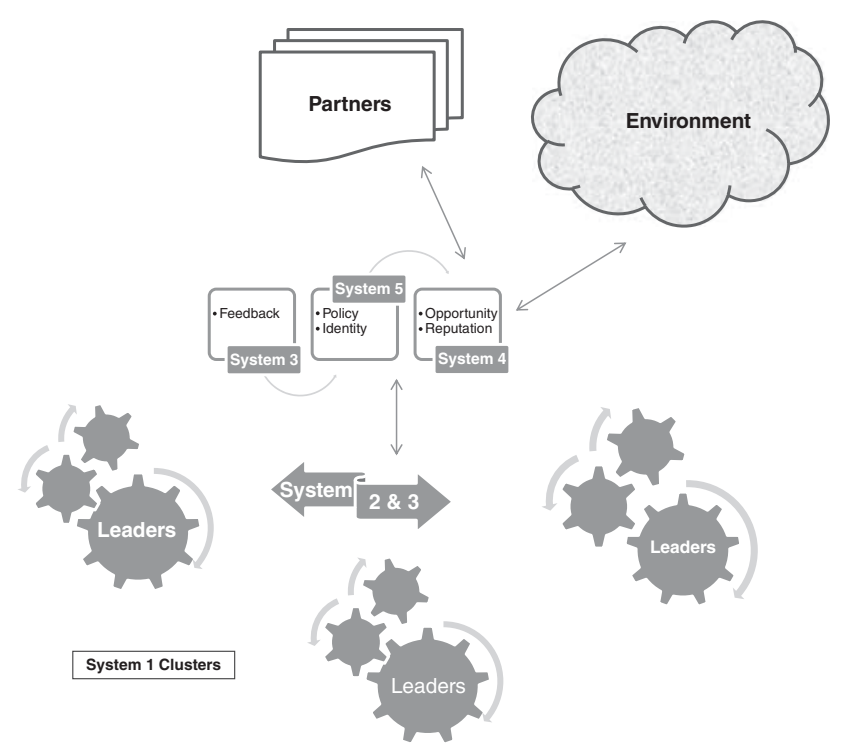

Figure 4 A sustainable system for university research.

there is not one, but multiple cultures of teaching, research, and knowledge transfer. Added to this, in the post-1992 sector, are rigidities imposed by national collective bargaining on conditions of service impacting on workload models.

System 3 collaborates with System 2 to promote synergy and keep a continuous overview of complexities in the system. Hoverstadt (2008) points out that for many decades, the view of management made popular by FW Taylor was the predominant paradigm for managers. Taylor's view was that, given autonomy, every worker would find his own way of carrying out a task. Logically, the best of these should be chosen and adhered to by all for the sake of efficiency (Taylor, 1967). However, as organisational activities have become more complex and specialised over time, most workers of today understand their jobs better than their immediate superiors. Rodgers (2007) points to a paradox that managers have formal authority to control business decisions but lack any control over the informal interpretations, expectations, and competence of their staff (particularly true of HEIs). Successful management, they argue, lies in embracing this paradox rather than attempting to resolve it. The concept of 'best practice' is no longer appropriate, particularly in the context of work that is high on ambiguity and uncertainty, such as teaching, research, and knowledge transfer. As an alternative to Taylorist approaches, Weaver \& Farrell (1998) discuss management as facilitation. The work of a facilitator would include identifying tasks workgroups need to complete; helping to encourage behaviour necessary to completing these tasks; encouraging effective interactions among groups of colleagues; and creating processes that enable planning of tasks and problem solving. Thus, a loose federation of work clusters might be a more effective structure than traditional departments and faculties (see Figure 4). Academics could collaborate in research and 
knowledge transfer, guided by professors in respect of RKS and enterprise coordinators in respect of knowledge transfer. System 2/3 would need to provide a vehicle of support for attraction and distribution of funding for these core activities.

Careful design of System 3 would be needed to ensure that timely feedback could be given to System 4 on success or otherwise of activities undertaken by System 1 units, coordinated through System 2. This will be challenging since there are multiple criteria for 'success', for example publication in quality journals, effective collaboration leading to exploitation through KT. If 'curiosity-driven' research is to be encouraged, the timescale over which success might be expected may vary considerably. Aspects of System 3 will need to be embedded within the clusters forming System 1, gaining cluster-specific knowledge but without falling into the trap of reinforcing fragmentation and sub-optimality. System 4 depends in part upon this feedback to engage in future planning. This sub-system will also need effective means to trawl the environment for opportunities, for example for research funding or new KT partnerships, which will be fed back to System 3 . System 4 must also be designed to (re)create the institution's public persona and provide information to System 5. System 5 is charged with responsibility for policymaking but will need to be designed in conjunction with System 2. It is necessary to ensure that a model of one-way communication of policy from a remote centre is avoided. System 5's task is not simply to declare what shall be done (or how) but to

\section{References}

ACKOFF RL and EMERY FE (1972) On Purposeful Systems. Aldine, Chicago, IL. ARGYRIS C and SCHÖN D (1978) Organizational Learning: A Theory of Action Perspective. Addison Wesley, Reading, MA.

AsHBY WR (1956) An Introduction to Cybernetics. Chapman \& Hall, London. AustRalian Government. (2009) Sustainable Research Excellence (SRE) initiative 2009-10. [WWW document] http://www.innovation.gov.au/ research/researchblockgrants/Pages/SustainableResearchExcellence. aspx (accessed 15 January 2013).

BANDURA A (1997) Self-efficacy: The Exercise of Control. Freeman, New York. BANDYOPADHYAY S and PATHAK P (2007) Knowledge sharing and cooperation in outsourcing projects - a game theoretic analysis. Decision Support Systems 43(2), 349-358.

BEDNAR PM (2007) Individual emergence in contextual analysis. Problems of individual emergence. Special issue of Systemica: Journal of the Dutch Systems Group 14: 1-6.

BEER S (1985) Diagnosing the System for Organizations. John Wiley, Chichester, UK.

BOURNEMOUTH UNIVERSITY (2012) Institute for Media \& Communication Research published aims. [WWW document] http://www.bournemouth .ac.uk/imcr/ipe/building-sustainability.html (accessed 15 January 2013).

CHATZOGLOU PD and VRAIMAKI E (2010) Building knowledge-sharing cultures: strategies, behaviour and incentive systems. International Journal of Applied Systemic Studies 3(3), 292-310.

CHAWLA D and JOSHI H (2010) Knowledge management practices in Indian industries - a comparative study. Journal of Knowledge Management 14(5), 708-725.

DePARTMENT for INTERNATIONAL DeVelopment (DFID) (2005) Communication of research: Guidance 7 Notes for Research Programme Consortia (2005). [WWW document] http://www.dfid.gov.uk/Site-search/?q=Department+ for+International+Development+(2005).+Communication+of+Research: +Guidance+7+Notes+for+Re (accessed 15 January 2013).

DEPARTMENT for INTERNATIONAL DEVELOPMENT (DFID) (2010) June 2010 note: Capacity building in research. [WWW document] http://www.ukcds cement together a common identity, which all those engaged within the system can espouse, that is. build a culture of sustainability. Only if this is achieved effectively can the problems of fragmentation and lack of effective research culture be overcome. Balance must be maintained on an on-going basis between variety in the HEI system and its interactions with the environment in order for sustainability to be achieved.

\section{Conclusion}

This paper has examined the concept of sustainability in relation to university research and has seen that the agenda of sustainability is growing in importance in the context of financial constraints experienced in many HE sectors around the world. It has been seen that a strong research culture is positively associated with success and that many institutions and funding agencies are engaged in capacity building activities. Studies have shown that RKS is vital for building effective research cultures, and that attitudes to knowledge sharing can be seen to vary between the pre- and post-1992 universities in the U.K. Examination of the differences between these sectors reveals a crucial role for professors in providing inspirational leadership, encouraging knowledge-sharing activity and thus enhancing the confidence and savoir-faire of other academics. We suggest that the VSM (Beer, 1985) could be a useful vehicle to examine structures and processes in HEIs in order to promote greater synergies and build stronger research cultures.

.org.uk/publication-Capacity_Building_in_Research_DFID_How_To_Note366.html (accessed 15 January 2013).

DOWNES P (2011) Principal's Blog, University of Dundee, U.K. Address to the Federation of Indian Chambers of Commerce and Industry summit on higher education in Delhi, December 2011. [WWW document] http://blog.dundee.ac.uk/principal/tag/international/ (accessed 15 January 2013).

ECONOMIC and SOCIAL RESEARCH COUNCIL (2012) Capacity building clusters. [WWW document] http://www.esrc.ac.uk/funding-and-guidance/ collaboration/knowledge-exchange/opportunities/Capacity-building.aspx (accessed 15 January 2013).

ESPEJO R and REYES A (2011) Organizational Systems: Managing Complexity with the Viable Systems Model. Springer-Verlag, Berlin Heidelburg.

FLIASTER A (2004) Cross-hierarchical interconnectivity: forms, mechanisms, and transformation of leadership culture. Knowledge Management Research \& Practice 2(1), 48-57.

HAZELKORN E (2004) Managing the University Community - Building a research strategy and funding it. Proceedings of EUA conference: Growing Research in New Universities, Barcelona, June 2004. http://www.eua.be/ eua/jsp/en/upload/Slides_Hazelkorn.1088176137290.ppt (accessed 15 January 2013).

HOVERSTADT P (2008) The Fractal Organization: Creating Sustainable Organizations with the Viable System Model. Wiley, Chichester, UK.

HuNG S-Y, DURCIKOVA A, LAIA H-M and LINA W-M (2011) The influence of intrinsic and extrinsic motivation on individuals' knowledge sharing behaviour. International Journal Human-Computer Studies 9(6), 415-427.

ISLAM MZ, AHMED SM, HASAN I and AHMED SU (2011) Organizational culture and knowledge sharing: empirical evidence from service organizations. African Journal of Business Management 5(14), 5900-5909.

MAHAMED ISMAIL NA (2012) Key Determinants of Research-Knowledge Sharing in UK Higher Education Institutions. PhD thesis: University of Portsmouth, UK, March 2012, unpublished. 
MahAmed ISMAIL NA, Xu M, WoOd M and WelCH C (2013) To share or not to share? Research-knowledge sharing in higher education institution: preliminary results. International Journal of Information Technology and Management (IJITM) 12(3-4), 169-188.

MCROY RG, FLANZER JP and ZLOTNIK JL (2011) Building Research Culture and Infrastructure (Building Social Work Research Capacity). Oxford University Press, New York.

OXFORD DICTIONARIES On-Line (2013) Definition of 'Sustainable'. [WWW document] http://oxforddictionaries.com/definition/english/sustainable? q=sustainable (accessed 15 January 2013).

RODGERS C (2007) Informal Coalitions. Palgrave Macmillan, Basingstoke, UK and New York.

SENGE P (1998) Sharing knowledge. Executive Excellence 15(6) $11-12$

\section{About the Authors}

Nor Ashmiza Mahamed Ismail obtained her Ph.D. in Business Management from the University of Portsmouth in 2012. She is currently a lecturer in Organisation Studies and Human Resource at Portsmouth Business School, University of Portsmouth. She is a Course Leader for the M.Sc. Human Resource Management Top-Up Programme and a member of the Business Education Research Group (BERG). She coordinates and teaches on a range of postgraduate and undergraduate units. She has gained over 10 years experience in academia. She has worked on consultancy projects, and run training courses for several organisations on a range of topics. Her areas of interest include knowledge management, organisational culture, people's behaviour, leadership, and organisational learning.

Christine Welch is a Visiting Research Fellow in the Operations \& Systems Management at Portsmouth Business School, and a Director and former President of the UK
STEHLIK T (2005) Building a university research culture - what does it look like? Proceedings of Research on Research conference 2005, Australian Technology Network of Universities. [WWW document] http://www.atn.edu.au/ researchconference/presentations.htm (accessed 15 January 2013).

TAYLOR FW (1967) The Principles of Scientific Management. Norton Library, W.W. Norton \& Company, Inc., New York.

WANG S and NOE RA (2010) Knowledge sharing: a review and directions for future research. Human Resource Management Review 20(2), 115-131.

WEAVER RG and FARRELL JD (1998) Managers as Facilitators. Berrett and Koehler, San Francisco, CA.

WELKER ME and COX AR (2006) A report on research activities at research universities (US). Research Management Review 15(1), 1-11.

WhITMORE J (1992) Coaching for Performance. Nicholas Brealey, London and Boston, MA.

Systems Society. Her research interests include critical systemic thinking, contextual analysis and organisational change, and she has published a number of book chapters and articles in these fields.

Mark Xu received his Ph.D. in MIS from the UK Open University in 1998, and is currently Reader in Information Management and Head of Operations \& Systems Management at the University of Portsmouth Business School. His specialist interests are in strategic information management and systems, eCommerce strategy and implementation, and ICT application and knowledge management. He leads several research and KTP projects on business intelligence, knowledge management and activating ageing workforce. He has over 60 publications in international journals such as Information \& Management, Information Processing \& Management. He serves as associate editor and in the editorial boards of a number of international journals. 